\title{
Key factors affecting the predation risk on insects on leaves in temperate floodplain forest
}

\author{
Michaela DROZDOVÁ ${ }^{1}$, JAN ŠIPOŠ ${ }^{1,2}$ and Pavel DROZD ${ }^{3}$ \\ ${ }^{1}$ Department of Ecology and Environmental Sciences, Faculty of Science, Palacky University, 77146 Olomouc, Czech Republic; \\ e-mail: michaela.drozdova@centrum.cz \\ ${ }^{2}$ Global Change Research Centre, Academy of Sciences of the Czech Republic, 60300 Brno, Czech Republic \\ ${ }^{3}$ Faculty of Science, University of Ostrava, 71000 Ostrava, Czech Republic; e-mail: pavel.drozd@osu.cz
}

Key words. Diptera, Calliphoridae, Calliphora vicina, insect predators, living prey, temporal and spatial differences, clumped dispersal of attacks

\begin{abstract}
The predation on insects on leaves was measured by direct observation using live larvae of Calliphora vicina (Diptera: Calliphoridae) as bait placed on 15 common species of woody plants in a floodplain forest in the temperate region. The predation rate was measured in terms of the proportion of the larvae that were missing or had been attacked after 30 min of exposure on leaves. Despite the fact that the important predators differed during the course of a season, the most frequently recorded predators were birds and ants and less frequently recorded wasps and spiders. Analysis of the pattern in the distribution of the attacks confirmed that it is best described by a negative binomial distribution, which corresponds to a clumped dispersal of predation. Based on the results of the best-fitted generalized additive model, we could not reject an equal probability of attacks on the different species of woody plants. Further, predation at the forest edge was notably higher than in the forest interior. The model also predicted marked variations in the incidence of attacks during the course of a day and a season, with the attacks occurring mainly in three periods during the year and two during the day. In general, the sampling method used could become the standard measure of the risk of insects living on trees being attacked by predators in future studies.
\end{abstract}

\section{INTRODUCTION}

Despite recent advances in ecological methodology and quantitative analysis for determining the nature of the complex interactions between organisms and their environment (Bolker et al., 2009; Kilkenny et al., 2009; Csillery et al., 2010), little attention has been paid to determining the potential of a multifactorial approach for studying the risk to insects from predation. Some aspects of predation risk on insects have been studied in both tropical (Olson, 1992; Berger \& Wirth, 2004; Koh \& Menge, 2006) and temperate ecosystems (Steward et al., 1988; Weseloh, 1988; Church et al., 1997; Haemig, 1999; Lichtenberg \& Lichtenberg, 2003). However, mostly single factors (or a class of factors, e.g. spatial, temporal and taxonomical) are tested separately for different groups of predators (e.g. birds: Bernays, 1997; Strong et al., 2000; spiders: Riechert \& Lawrence, 1997; Lang et al., 1999; ants: Barton, 1986; Leponce et al., 1999).

For example, there are significant differences in the predation risk on different species of trees because of differences in their attractiveness to predators, particularly for tropical rainforests (Janzen, 1966; Novotny et al., 1999; Basset, 2001). Differences in predation risk are correlated with the abundance of herbivores on three species of Salix (Ishihara \& Ohgushi, 2008) in a temperate ecosystem. There are also experimental studies on spatial variability in predation risk along vertical (Weseloh, 1988; Basset, 2003) and horizontal gradients, such as in the interior of a closed canopy forest compared with that at the edge of the forest or in the open (Koh \& Menge, 2006; Valladares et al., 2006). There are few studies on the diurnal and seasonal activity of predators (Barton, 1986; Kaspari \& Joern, 1993; Reichert \& Lawrence, 1997; Remmel et al., 2011) and these are only occasionally tested (temperate: Lichtenberg \& Lichtenberg, 2003; Remmel et al., 2009; tropics: Richards \& Coley, 2007). This is despite the logical expectation that the risk of predation is likely to vary depending on the time of day or year, for example, due to differences in temperature and seasonal changes in ecosystems (Bernays, 1997; Lill \& Marquis, 2001).

The results of the experiments cited above have been criticised (e.g. Sih et al., 2000) for underestimating the interactions between the factors. Unfortunately, it is not possible to produce a simple synthesis or compare the results of the different studies because they were obtained using different methods. Two key methods are used for measuring the risk of predation on trees. Free access of predators to prey is prevented by using exclosure experiments (Marquis \& Whelan, 1994; Sipura, 1999; Berger \& Wirth, 2004). This method is used mainly to study complex multitrophic interactions, such as bottom-up effects and top-down effects, and fitness of the prey or host plant foraged by the herbivore (Gunnarsson, 1996; Strong et al., 2000). In contrast, experiments using various types of baits (Olson, 1992; Karhu \& Neuvonen, 1998; Novotny et al., 1999; Lichtenberg \& Lichtenberg, 2003) allow direct contact between the prey and predator and provide more information on the characteristics of the taxa or 
guilds of predators, such as their species structures and the effects of prey dispersal (Church et al., 1997; Beauchamp, 2002), vegetation structure (Gunnarsson, 1996) or seasonal changes (Lang et al., 1999; Lill \& Marquis, 2001; Lichtenberg \& Lichtenberg, 2003).

In addition to the aforementioned factors affecting the accumulative risk of predation in space and time, many authors note that the risk of predation is greater when prey is abundant (e.g. Crawley, 1975; Turchin et al., 1999; Abrams \& Ginsburg, 2000; Lombaert et al., 2006). They found that predation risk affects prey behaviour and leads to avoidance and dispersal of the prey (Jeffries \& Lawton, 1984, Berdegue et al., 1996; recently, Skelhorn et al., 2011; Gonthier, 2012). On the other hand, there is a lack of information confirming that the distribution in space of the attacks by predators is patchily distributed even though the searching patterns of predators are well known.

It is clear from the above that there are very few multifactorial models that include various predators and the interactions between factors and those published are mainly for tropical rainforests and there are no similar studies for temperate ecosystems. Our goal, therefore, was to identify the significant factors affecting predation on insects on the leaves of trees and then develop a complex model for assessing the predation risk. We tested the following ecological variables: (a) tree species (15 tree species with varying herbivore species abundances and diversities), (b) habitat (forest interior and edge), (c) time of day, and (d) time of year.

\section{MATERIAL AND METHODS}

\section{Study site}

This field study on predation was carried out in a lowland floodplain forest within the Poodri Protected Landscape Area (total, 300 ha; $18^{\circ} 03-13^{\prime} \mathrm{E}, 49^{\circ} 42-48^{\prime} \mathrm{N}$; Northern Moravia, Czech Republic). The area included three fragments of primary floodplain forest in close proximity to the regional capital of Ostrava along a $20-\mathrm{km}$ embankment of the meandering River Odra. The area is characterized by flooded meadows and a number of shallow ponds. The forest vegetation consists of Quercus, Ulmus, Tilia, Prunus and Fraxinus.

\section{Field experiment}

Our sampling design was that previously suggested for comparing the predation risk between temperate floodplain forest and tropical lowland rainforest (Novotny et al., 2006). For the experiments, 15 locally common species of woody plants (Acer campestre L., Acer platanoides L., Alnus glutinos (L.) Gaertn., Alnus incana (L.) Moench., Carpinus betulus L., Corylus avellana L., Fraxinus excelsior L., Padus avium Mill., Populus tremula L., Quercus robur L., Sambucus nigra L., Swida sanguinea (L.) Opiz., Tilia cordata Mill., Ulmus glabra Huds., and Ulmus laevis Pallas) typical of floodplain forests in the temperate region, were selected.

The ecological attributes of the above woody plants (i.e. the abundance and diversity of herbivores as well as the abundance and frequency of the trees) were adopted from our plant-herbivore study performed simultaneously with the predation experiments. Only those folivorous insects that were feeding were hand-collected from the foliage of 15 species of trees throughout the 1999-2001 growing seasons. This resulted in
$150 \mathrm{~m}^{2}$ of foliage being inspected per species of tree. The estimates of the species richness and frequency of woody plants were based on total number of woody stems in $6225 \times 25 \mathrm{~m}$ quadrats (for details, see Novotny et al., 2006).

Predation risk was estimated by recording whether bait placed on leaves is attacked or missing (see Olson, 1992; Novotny et al., 1999). The bait consisted of live larvae (last instar; size, $1-1.5 \mathrm{~cm}$ ) of the blowfly Calliphora vicina Robineau-Desvoidy (Diptera: Calliphoridae). These larvae are palatable and very vulnerable to attack (Lundgren et al., 2009) and thus previously used as model artificial palatable prey in several predator-prey experiments (Wilson et al., 1990; Lundgren et al., 2009; Remmel et al., 2009). Further, the last instars are of a suitable size for both vertebrate and invertebrate predators (Lang et al., 1999).

In each experiment (sample), 25 living larvae were pinned onto each tree for $30 \mathrm{~min}$ (one larva per twig separated by a minimum distance of about $25-30 \mathrm{~cm}$ ) at breast height using entomological pins inserted into veins on the upper surface of leaves. Attaching larvae by pins to leaf veins prevents them from accidental falling off leaves and makes the removal of the pins by invertebrate predators impossible. The pins were marked with small coloured tags to avoid missing those that were accidentally dislodged. Baits continued to move actively throughout the duration of the experiment. After 30-min, during which we moved away from the tree upon which the test was performed, the presence of predators or missing larvae were recorded (the proportion of larvae attacked per tree was used as a response variable). The experimental sites were systematically changed during the course of the year to eliminate the possibility of birds learning to find larvae by searching for tags. Based on our experiences from a preliminary study in 2001 and other published experiments (Lichtenberg \& Lichtenberg, 2003), pins that disappeared (confirmed after carefully searching for baits on the ground and nearby vegetation) were assumed to reflect bird predation. On the other hand, ants and wasps, which were the most frequently recorded invertebrate predators, were always observed feeding on the baits.

In total, 300 experiments with 7500 baits were conducted from May-September 2002 between 09:00 to 18:00 h. The following factors were recorded in each experiment: time of day (Hour), time of year (Day), species of woody plant (Species) and habitat (MicHab, i.e. forest interior or edge). Samples that were more than $20 \mathrm{~m}$ away from the edge of the forest were regarded as being in the interior of the forest. To maximise the balance in the design, the experiments were replicated twice each month for each species of tree species and type of habitat.

\section{Data analysis}

As a patchy dispersal is very often recorded in nature because resources are not uniformly distributed (Potthoff et al., 2006), we expected that the dispersal of predator attacks would follow a negative binomial distribution. Thus, the index of dispersion (the variance-to-mean ratio), Morisita's index of dispersion and goodness of fit to a negative binomial distribution with aggregation parameter $k$ estimated by maximum likelihood were used to identify the patterns in the distribution of the attacks (Krebs, 1999). Index values significantly higher than 1 (or 0 for Morisita's index) indicated clumped (patchy) distributions. The dispersal of the attacks was analysed separately for each combination of habitat (interior, edge), month and time interval $(2 \mathrm{~h}$ per interval) to distinguish between spatial and temporal distributions. For this reason, we used additional data from 2001 (not applicable for the other analyses due to the low number of replications for each combination). This approach allowed us to increase the number of samples for each combination and 


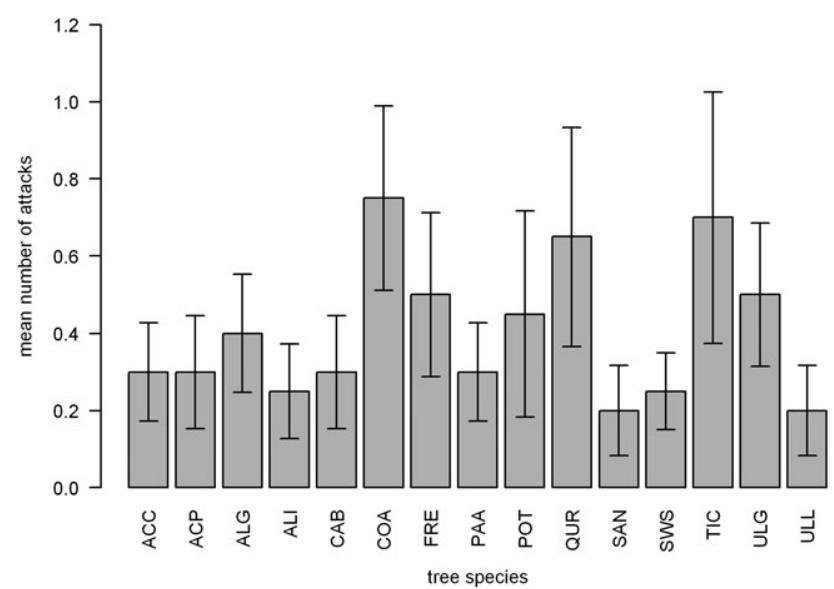

Fig. 1. The mean $( \pm \mathrm{SE})$ of the number of attacks recorded per experiment on the different species of woody plants studied. ACC - Acer campestre; ACP - Acer platanoides; ALG - Alnus glutinosa; ALI - Alnus incana; CAB - Carpinus betulus; COA - Corylus avellana; FRE - Fraxinus excelsior; PAA - Padus avium; POT - Populus tremula; QUR - Quercus robur; SAN Sambucus nigra; SWS - Swida sanguinea; TIC - Tilia cordata; ULG - Ulmus glabra; ULL - Ulmus laevis.

improve the validity of the results. However, we had to omit some combinations because of the low number of attacks.

Generalized additive models (GAM) were used to investigate the effect of the factors studied on the probability of attack. For those cases when the response variable was a probability and the model indicated overdispersion (the dispersion index was approximately 1.7 for our data), a quasibinomial distribution gave more reasonable results. The numerical variables Hour and Day were smoothed by using thin plate regression splines (Wood, 2006). The basis dimensions for both the terms were selected manually ( $\mathrm{k}=4$ for Hour and $\mathrm{k}=6$ for Day) using the generalized cross validation (GCV) criterion, which is one of the best ways of estimating smoothing parameters. This crite- rion was also used for manual selection of the best parameters in the additive models (for more details, see Wood, 2006). All factors tested were added sequentially to the model using GCV and Cp Mallow's statistics criteria for model parameter selection (Mallows, 1973; Hocking, 1976) and the best fitting model comparisons (the lowest $\mathrm{Cp}$ and GCV values indicated the most parsimonious model).

The final model of the probability of attack was constructed based on the GCV, and Mallow's Cp ranking statistics. Both criteria are based on the maximum parsimony approach recently suggested for model selection, but mixing of criterion-based selection with standard measurement of significance is not recommended (Anderson, 2008).

All analyses were performed using R software 2.14.0 (R core development team, 2011) and several specific libraries: lattice 0.20-0 (Deepayan, 2008), vegan 2.0-1 (Oksanen et al., 2011), gam 1.04.1 (Hastie, 2011) and ved 1.2-12 (Meyer et al., 2011).

\section{RESULTS}

A total 119 of the 7500 baits (1.6\%) were attacked by predators, meaning that on average, 0.4 baits were attacked per experiment (standard deviation $(\mathrm{SD})=0.85$; standard error $(\mathrm{SE})=0.05$; maximum $=6$ baits per experiment). The dominant groups of predators were birds (59.7\%), ants (13.4\%), Heteroptera (11.8\%), Mecoptera (5.9\%) and wasps (4.2\%). Several other groups were recorded occasionally (spiders and carabid beetles). The maximum predation risk, measured as the average number of baits attacked per experiment, was recorded on Corylus avellana (0.75), Tilia cordata (0.7) and Quercus robur (0.65) and the minimum on Ulmus laevis (0.20) and Sambucus nigra (0.20) (Fig. 1).

Predation risk correlated neither with the abundance and frequency of particular species of trees nor with abundance and diversity of insect herbivores (Pearson's correlation coefficient was the highest for abundance of herbivores, $r=0.43 ; \mathrm{p}>0.1)$.
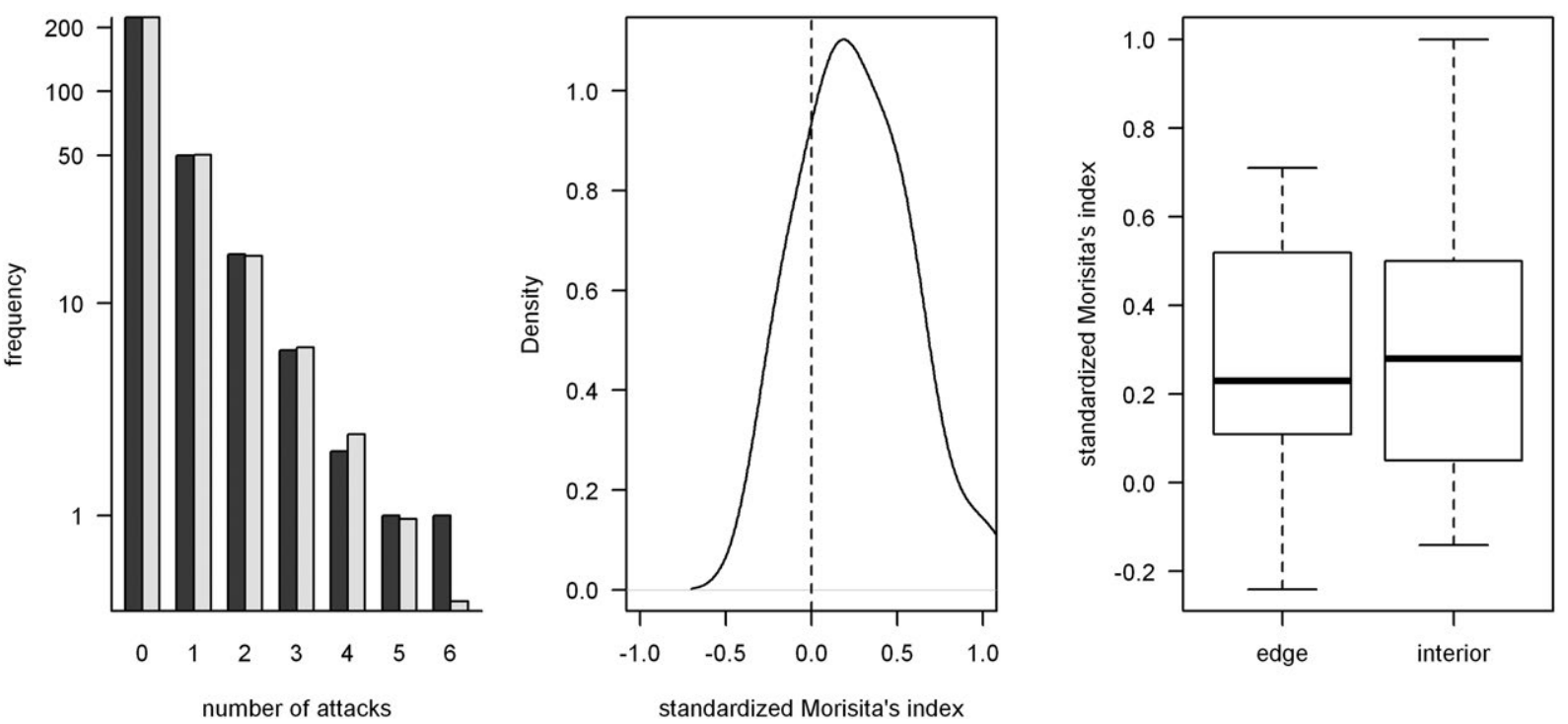

Fig. 2. The observed (dark grey) and theoretical negative binomially distributed (light grey) frequencies of attacks per tree plotted on a logarithmic scale (left), the probability density (empirical density function) of the standardized Morisita's indices (middle) for each combination of temporal and spatial variables (positive values indicates a patchy distribution), and a box plot comparing the standardized Morisita's indices for the edge and interior of the forest (right). 

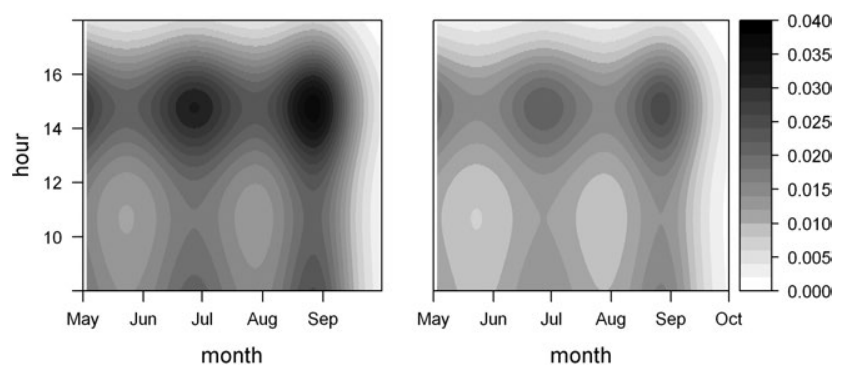

Fig. 3. A contour plot with predicted probabilities of attack by predators (grey scale on the right) for the most parsimonious model, including type of habitat (left, forest edge; right, forest interior), time of day and time of year.

The results of all the tests used for determining the pattern of the attacks were consistent with our prediction of patchy dispersal. We found the variance-to-mean ratio of attacks per experiment to be significantly greater than 1 (I $\left.=1.793, \chi^{2}{ }_{299}=536.0, \mathrm{p}<0.0001\right)$ and the Morisita's index to be 2.98 (standardized Morisita's index = 0.5026); further, the goodness-of-fit test (maximum likelihood estimate of $\left.k=0.506, \chi^{2}{ }_{2}=0.011, \mathrm{p}=0.995\right) \mathrm{did}$ not support a rejection of a negative binomial distribution (Fig. 2). Such outcomes can result from a patchy dispersal in time (attacks occur mainly within specific time intervals). However, we observed similar results for the pattern of distribution of attacks for each combination of the temporal and spatial variables. Nearly $75 \%$ of the standardized Morisita's indices calculated were positive (indicating a patchy dispersal). Negative indices (indicating a uniform dispersal) and indices equal to 0 (indicating a random dispersal) were found only for samples with a low number of attacks and the most frequent were for samples recorded in autumn.

The best fitting GAM model chosen by forward selection included three terms: microhabitat, time of day and day of the year (Table 1). All terms in the final model have weak but significant statistical support from the
TABLE 1. Values of the statistics used in the selection of the best GAM model (GCV - generalized cross validation; $\mathrm{Cp}-$ Mallow's Cp; DevExpl - explained deviance).

\begin{tabular}{lccc}
\hline Model & GCV & Cp & DevExpl \\
\hline Null & 1.2594 & 377.70 & 0.000 \\
Species & 1.3039 & 390.20 & 0.059 \\
Hour & 1.2358 & 370.67 & 0.037 \\
MicHab & 1.2328 & 369.82 & 0.028 \\
Day & 1.2098 & 362.79 & 0.070 \\
MicHab + Hour & 1.2182 & 365.37 & 0.057 \\
MicHab + Day & 1.2046 & 361.21 & 0.080 \\
Hour + Day & 1.1917 & 357.23 & 0.100 \\
MicHab + Hour + Day & 1.1903 & 356.74 & 0.107 \\
\hline
\end{tabular}

analysis of deviance ( $\mathrm{p}$-value $\mathrm{e}_{\text {Michab }}=0.096, \mathrm{p}$-value $\mathrm{Hour}_{\mathrm{H}}=$ $0.067, \mathrm{p}-$ value $\left._{\text {Day }}=0.049\right)$. In contrast, we could not reject the hypothesis of an identical risk of predation on all species of woody plants. The final model predicts the risk of predation is highest at the edge of forest during late August and early September between 13:00-15:00 h (Fig. $3)$.

Despite the overall low number of records of predation, we performed separate analyses for invertebrate and vertebrate predators, and found apparent temporal differences between predation by arthropods and birds. This was confirmed by the lack of a correlation between the two groups (Pearson's correlation coefficient $\mathrm{r}=-0.22$, $\mathrm{t}$ $=-0.99, \mathrm{df}=19, \mathrm{p}$-value $=0.3349)$. A peak in predation by birds was recorded during the morning in May and June while arthropods dominated in July between the hours of 09:00 to 11:00 and 15:00 to 17:00 (Fig. 4).

\section{DISCUSSION}

Our experiments on predation revealed that the distribution of attacks on bait attached to leaves was clumped, with no significant differences between species of trees
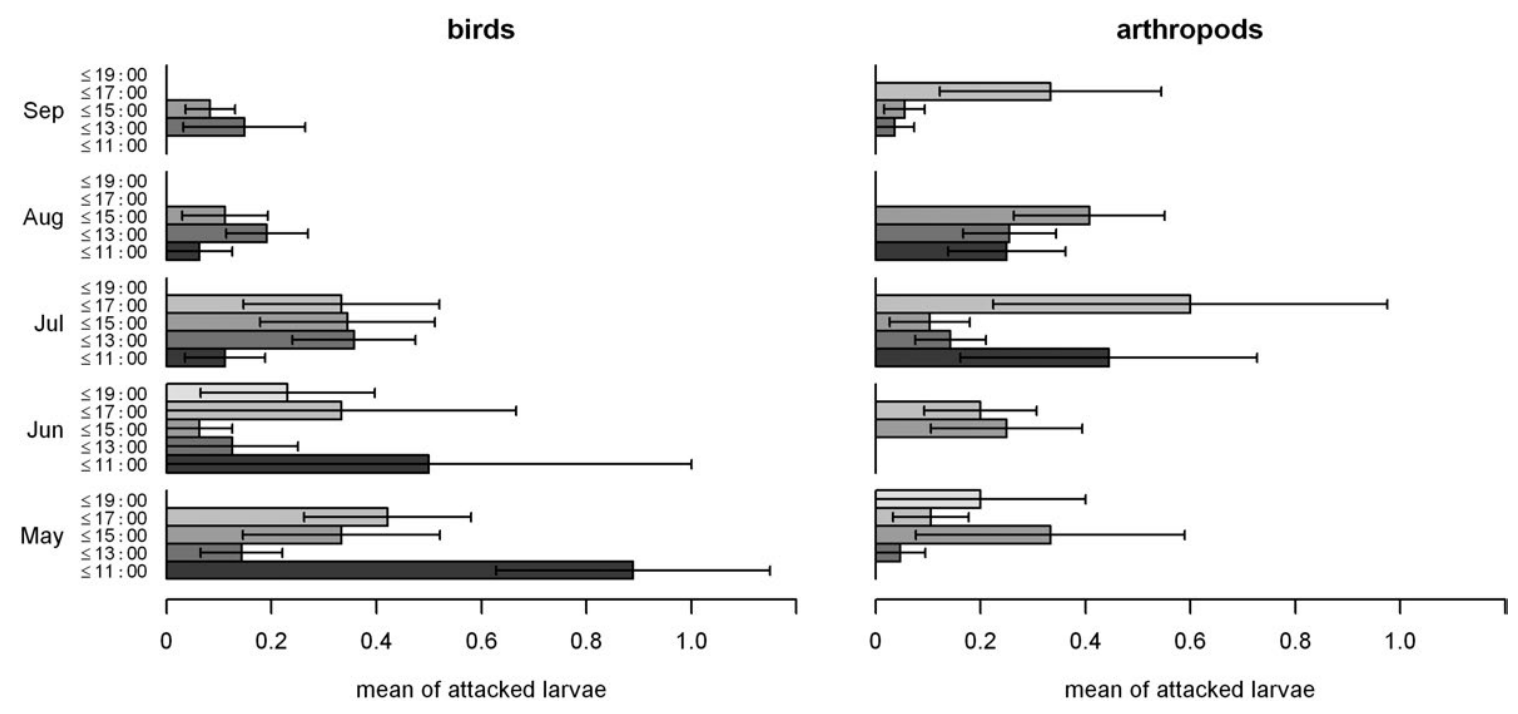

Fig. 4. A comparison of the mean $( \pm \mathrm{SE})$ of the number of attacks recorded that were attributed to birds and arthropods at different times of the day in different months of the season (right-closed intervals). 


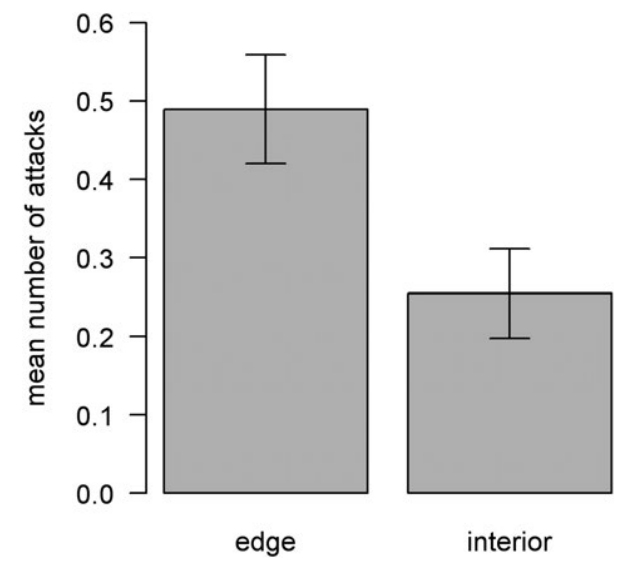

Fig. 5. The mean $( \pm \mathrm{SE})$ of the number of attacks recorded on trees at the edge and interior of the forest.

but an important effect of habitat (higher predation risk at the edge than in the interior of the forest), time of the day and season. The important predators were birds and ants, but the frequency of their attacks varied during the year and was dependent on their seasonal activity (cf. epigeic predators, Šipoš et al., 2011).

The analyses of the spatial distribution of attacks indicate that rates of predation in patches with equal densities of prey differed. This probably reflects random search for the first prey and then systematic searching in the surrounding area. Such behaviour is often mentioned as typical of birds and ants (Church et al., 1997; Beauchamp, 2002). On the other hand, these results should be interpreted cautiously, because very few attacks were recorded and we did not distinguish between these two groups in the analyses of the spatial distributions of the attacks

As expected, our data did not provide a basis for rejecting the hypothesis of a non-random distribution of attacks on the different species of woody plants. This result is also supported by the non significant correlations between the average predation risk and features of the different species of trees (abundance, frequency, and number of herbivores and their diversity). Unlike parasitoids (Iwao et al., 2001), true predators probably have not evolved close interspecific interactions with plants in forests in temperate regions (Olsson et al., 2001) but have in tropical rainforests (Basset, 1995, 1996; Novotny et al., 1999). Significant differences were found only for those species like ants, which have a mutualistic relationship with plants (Janzen, 1966; Floren \& Linsenmair, 1997; Fiala et al., 1994; Di Gusto et al., 2001).

The greater predation risk at the edge of the forest (Fig. 5) predicted by our final model, was previously recorded for the same predators as we studied (Olson, 1992; Haemig, 1999; Lichtenberg \& Lichtenberg, 2003; Valladares et al., 2006). This may be due to a greater abundance and activity of insects (mostly herbivores) and more favourable microhabitat conditions at the edges of forests (Murcia, 1995; Didham et al., 1996; Cadenasso \& Pickett, 2000; Zheng \& Chen, 2000; Wirth et al., 2008). Moreover, wasps can have a notable effect at the edges of forest because it is warmer there than in forests (Steward et al., 1988; Lichtenberg \& Lichtenberg, 2003).

Despite the fact that we could not include the entire range of diurnal and seasonal differences in predatory activity (see Fig. 3), our model did indicate three peaks of predation risk during the course of the growing season and two during the day. There are only a limited number of incidental records of the diurnal variation in the predation risk (Barton, 1986; Novotny et al., 1999; Berger \& Wirth, 2004) and our model cannot predict the risk of predation either at night or early in the morning when there is a peak in the incidence of predation by birds (e.g. Hutto, 1981). However, a greater incidence predation early in the morning was partially apparent in the prediction of our model (i.e., the decline in the rate of predation that occurred after the expected early morning peak) and particularly notable was a shift in peak predation during the course of the year (Fig. 3, dark grey areas at the bottom of the left figure). Montllor \& Bernays (1993) state that the high predation risk recorded at midday is due to the greater activity of invertebrates then because both the temperature and relative humidity are high at that time. At night the expectation is that the foraging activity of ants and other invertebrate predators is likely to be very low in ecosystems in temperate regions (Bernstein, 1979; Traniello, 1989). Moreover, for predators that orientate visually (including insectivorous birds) searching for prey is less effective at night. However, there is little experimental data on this, because recording attacks by predators at night is difficult. Novotny et al. (1999) used termites (Microcerotermes biroi) as bait to determine the risk of herbivorous insects being killed by predators during day and night in Papua New Guinea rainforests. They record marked differences in the composition of predators, but the differences in the probabilities of being attacked were not significant. Their results differ from those of Berger \& Wirth (2004) who used exclosure experiments and revealed that the predation pressure on phasmids in rainforest in Panama was significantly higher at night than during the day ( $\mathrm{p}$-value $<0.001)$.

Consistent with the results of Holmes et al. (1979), Lill \& Marquis (2001) and Lichtenberg \& Lichtenberg (2003) and our unpublished data from the previous year (not used because of an unbalanced design for species and daytime), we recorded a greater predation risk at the beginning of May (using extrapolation, we estimated that the peak occurred at the end of April), with birds at that time the most important predators, at the end of June it was birds and ants and at the end of August wasps, as colonies of these insects were large and very active (MacDonald \& Matthews, 1981; Stamp \& Bowers, 1996).

Measuring the risk of predation is technically difficult and it is likely that the method used and the features measured could have biased the results. For this reason, exclosure and predator removal experiments are generally regarded as the best way of estimating the real effect of predation (absolute predation risk). However, it is important to note that our experiments were performed under identical conditions for each factor combination and that, 
it is thus possible to correlate relative differences in the number of attacks with predator activity within a study site (Novotny et al., 1999). Another issue usually discussed is the most suitable bait (Kaspari \& Joern, 1993; Berger et al., 2006). For generalist predators like birds and ants, size (Lang et al., 1999; Di Giusto et al., 2001; Mänd et al., 2007; Remmel \& Tammaru, 2009; Remmel et al., 2011), palatability (Skelhorn \& Rowe, 2006; Lundgren et al., 2009), mobility (Eubanks \& Denno, 2000) and colour (Church et al., 1997) are the main characteristics determining the probability of a bait being attacked. The most widely used baits in studies in tropical forest are termites, which are highly palatable prey for ants and all the other important predators of herbivorous insects in the tropics (Olson, 1992; Leponce et al., 1999; Novotny et al., 1999). However, the baits most widely used in ecosystems in temperate regions are caterpillars (Bernays, 1997; Lill \& Marquis, 2001; Lichtenberg \& Lichtenberg, 2003). The larvae of Calliphora vicina, which we used in our experiments, are probably analogous to termite baits used in the tropics (see Lundgren et al., 2009). A very important characteristic is that the larvae attached to leaves are highly active and therefore likely to attract predators that orientate visually when searching for prey. It is known that the mobility of prey can increase their risk of predation by beetles (e.g. Marston et al., 1978; Eubanks \& Denno, 2000) and spiders (Reichert \& Lawrence, 1997). Finding prey by responding to visual stimuli is recorded for birds (Beauchamp, 2002) and wasps (Bernays, 1997). In most cases, the mobility of the prey seems to be more important than its nutritional quality (Bernays, 1997; Eubanks \& Denno, 2000; Beauchamp, 2002). Although Calliphora larvae are not herbivores, the range of predators we recorded attacking them does not differ from the predator composition recorded in the previously cited experiments that used caterpillars. The low frequency of bird predation recorded by Lichtenberg \& Lichtenberg (2003) may be because they did not include in their results the baits that disappeared and the baits were attached to the undersides of the leaves.

Despite these difficulties, our complex model of the risk of insects being killed by predators in forests in temperate regions is based on the results of very simple experiments using baits that are suitable for most insectivorous generalists. We consider this method to be very useful and believe that it is suitable for use as a standard method for directly measuring predation risk in the future.

ACKNOWLEDGEMENTS. We are very grateful to T. Kocurek and B. Varkockova for help with the field experiments and three anonymous referees for their constructive comments. The project was supported by the Grant Agency of the Academy of Sciences of the Czech Republic (GAAV B6187001), the Grant Agency of the Czech Republic (GACR 206/99/1112, GACR 206/07/0811), CzechGlobe, reg. no. CZ.1.05/1.1.00/02.0073, LC06073 and the Institute of Environmental Technologies project, reg. no. CZ.1.05/2.1.00/03.0100.

\section{REFERENCES}

Abrams P.A. \& Ginzburg L.R. 2000: The nature of predation: prey dependent, ration dependent or neither? - Trends Ecol. Evol. 15: 337-341.

Anderson D.R. 2008: Model Based Inference in the Life Sciences: A Primer on Evidence. Springer, New York, 184 pp.

BARTON A.M. 1986: Spatial variation in the effect of ants on an extrafloral nectary plant. - Ecology 67: 495-504.

BASSET Y. 1995: Arthropod predator-prey ratios on vegetation at Wau, Papua New Guinea. - Sci. New Guinea 21: 103-112.

BASSET Y. 1996: Local communities of arboreal herbivores in Papua New Guinea: predictors of insect variables. - Ecology 77: 1906-1919.

BASSET Y. 2001: Communities of insect herbivores foraging on saplings versus mature trees of Pourouma bicolor (Cecropiaceae) in Panama. - Ecology 129: 253-260.

Basset Y., Hammond P.M., Barrios H., Holloway J.D. \& Miller S.E. 2003: Vertical stratification of arthropod assemblages. In Basset Y., Novotny V., Miller S.E. \& Kitching R.L. (eds): Arthropods of Tropical Forests: Spatio-Temporal Dynamics and Resource use in the Canopy. Cambridge University Press, Cambridge, pp. 17-27.

BEAUCHAMP G. 2002: Higher-level evolution of intraspecific flock-feeding in birds. - Behav. Ecol. Sociobiol. 51: 480-487.

Berdegue M., Trumble J.T., Hare J.D. \& Redak R.A. 1996: Is it enemy-free space? The evidence for terrestrial insects and freshwater arthropods. - Ecol. Entomol. 21: 203-217.

Berger J.R. \& WirTh R. 2004: Predation-mediated mortality of early life stages: A field experiment with nymphs of herbivorous stick insect (Metriophasma diocles). - Biotropica 36: 424-428.

Berger D., Walters R. \& Gotthard 2006: What keeps insects small? - Size dependent predation on two species of butterfly larvae. - Evol. Ecol. 20: 575-589.

BERNAYs E.A. 1997: Feeding by lepidopteran larvae is dangerous. - Ecol. Entomol. 22: 121-123.

BERNSTEIN R.A. 1979: Schedules of foraging activity in species of ants. - J. Anim. Ecol. 48: 921-930.

Bolker B.M., Brooks M.E., Clark C.J., Geange S.W., Poulsen J.R., Stevens M.H.M. \& White J.S.S. 2009: Generalized linear mixed models: a practical guide for ecology and evolution. - Trends Ecol. Evol. 24: 127-135.

Cadenasso M.L. \& Pickett S.T.A. 2000: Linking forest edge structure to edge function: mediation of herbivore damage. J. Ecol. 88: 31-44.

Church S.C., Jowers M. \& Allen J.A. 1997: Does prey dispersion affect frequency-dependent predation by wild birds? Oecologia 111: 292-296.

CRAWLEY M.J. 1975: The numerical responses of insect predators to changes in prey density. - J. Anim. Ecol. 44: 877-892.

Csillery K., Blum M.G.B., Gaggiotti O.E. \& Francois O. 2010: Approximate Bayesian Computation (ABC) in practice. - Trends Ecol. Evol. 25: 410-418.

DeEpayan S. 2008: Multivariate Data Visualization with $R$. Springer, New York, 265 pp.

Didham R.K., Ghazoul J., Stork N.E. \& Davis A.J. 1996: Insects in fragmented forests: a functional approach. Trends Ecol. Evol. 11: 255-260.

Di Giusto B., Anstett M.C., Dounias E. \& McKey D.B. 2001: Variation in the effectiveness of biotic defence: the case of an opportunistic ant-plant protection mutualism. - Oecologia 129: $367-375$. 
Eubanks M.D. \& Denno R.F. 2000: Health food versus fast food: the effects of prey quality and mobility on prey selection by a generalist predator and indirect interactions among prey species. - Ecol. Entomol. 25: 140-146.

Fiala B., Grunsky H., Maschwitz U. \& Linsenmair K.E. 1994: Diversity of ant-plant interactions: protective efficacy in Macaranga species with different degrees of ant association. - Oecologia 97: 186-192.

Floren A. \& LinsenMair K.E. 1997: Diversity and recolonization dynamics of selected arthropod groups on different tree species in a lowland rainforest in Sabah, Malaysia with special reference to Formicidae. In Stork N.E., Adis J. \& Didham R.K. (eds): Canopy Arthropods. Chapman \& Hall, London, pp. 344-381.

GonTHIER D.J. 2012: Do herbivores eavesdrop on ant chemical communication to avoid predation? - PLoS One 7: e28703. doi:10.1371/journal.pone.0028703.

GunNARSSON B. 1996: Bird predation and vegetation structure affecting spruce-living arthropods in a temperate forest. $-J$. Anim. Ecol. 65: 389-397.

Haemig P.D. 1999: Predation risk alters interactions among species: competition and facilitation between ants and nesting birds in a boreal forest. - Ecol. Lett. 2: 178-184.

Hastie T. 2011: Generalized Additive Models. R package version 1.04.1.

HockING R.R. 1976: A biometrics invited paper. The analysis and selection of variables in linear regression. - Biometrics 32: $1-49$.

Holmes R.T., Schultz J.C. \& Nothngale P. 1979: Bird predation on forest insects: an exclosure experiment. - Science 206: 462-463.

HutTo R. 1981: Temporal patterns of foraging activity in some wood warblers in relation to the availability of insect prey. Behav. Ecol. Sociobiol. 9: 195-198.

IsHiHARA M. \& OHGUSHI T. 2008: Enemy-free space? Host preference and larval performance of a willow leaf beetle. Popul. Ecol. 50: 35-43.

Imao K., NaKamura S. \& Ohsaki N. 2001: Plant-based host preferences and larval competition of the tachinid parasitoid Epicampocera succinata. - Popul. Ecol. 43: 149-155.

JANZEN D.H. 1966: Coevolution of mutualism between ants and acacias in Central America. - Ecology 20: 249-275.

JefrRies M.J. \& Lawton J.H. 1984: Enemy free space and the structure of ecological communities. - Biol. J. Linn. Soc. 23: 269-286.

Karhu K.J. \& Neuvonen S. 1998: Wood ants and a geometrid defoliator of birch: predation outweighs beneficial effects through the host plant. — Oecologia 113: 509-516.

Kaspari M. \& Joern A. 1993: Prey choice by three insectivorous birds: reevaluating opportunism. - Oikos 68: 414-430.

Kilkenny C., Parsons N., Kadyszewski E., Festing M.F.W., Cuthill I.C., Fry D., Hutton J. \& Altman D.G. 2009: Survey of the quality of experimental design, statistical analysis and reporting of research using animals. - PloS One 4: e7824.

Koh L.P. \& Menge D.N.L. 2006: Rapid assessment of Lepidoptera predation rates in Neotropical forest fragments. - Biotropica 38: 132-134.

KreBs C. 1999: Ecological Methodology. Benjamin Cummings, Menlo Park, CA, 620 pp.

LANG A., Filser J. \& Henschel J.R. 1999: Predation by ground beetles and wolf spiders on herbivorous insects in a maize crop. - Agric. Ecosyst. Environ. 72: 189-199.

Leponce M., Roisin Y. \& Pasteels J.M. 1999: Community interactions between ants and arboreal-nesting termites in New Guinea coconut plantations. - Insectes Soc. 46: 129-130.
Lichtenberg J.S. \& Lichtenberg D.A. 2003: Predation of caterpillars on understory samplings in an Ozark forest. - Southeast. Nat. 2: 423-432.

LILL J.T. \& MARQUIS R.J. 2001: The effects of leaf quality on herbivore performance and attack from natural enemies. Oecologia 126: 418-428.

LOMBAERT E., Boll R. \& LAPChIN L. 2006: Dispersal strategies of phytophagous insects at a local scale: adaptive potential of aphids in an agricultural environment. - BMC Evol. Biol. 6: 75 .

Lundgren J.G., Haye T., Toepfer S. \& Kuhlmann U. 2009: A multifaceted hemolymph defence against predation in Diabrotica virgifera virgifera larvae. - Biocontr. Sci. Technol. 19: $871-880$.

MacDonald J.F. \& Matthews R.W. 1981: Nesting biology of the eastern yellowjacket, Vespula maculifrons (Hymenoptera: Vespidae). - J. Kansas Entomol. Soc. 54: 433-457.

Mallows C.L. 1973: Some comments on Cp. - Technometrics 15: 661 .

MÄNd T., TAmmaru T. \& Mappes J. 2007: Size dependent predation risk in cryptic and conspicous insects. Evol. Ecol. 21: 485-498.

Marquis R.J. \& Whelan C.J. 1994: Insectivorous birds increase growth of white oak through consumption of leaf-chewing insects. - Ecology 75: 2007-2014.

Marston N.L., Schmidt G.T., Biever K.D. \& Dickerson W.A. 1978: Reaction of five species of soybean caterpillars to attack, by the predator, Podisus maculiventris. - Environ. Entomol. 7: 53-56.

Meyer D., Zeileis A. \& HorniK K. 2011: Visualizing Categorical Data. R package version 1.2-12.

Montllor C.B. \& Bernays E.A. 1993: Invertebrate predators and caterpillar foraging. In Stamp N.E. \& Casey T.M. (eds): Caterpillars: Ecological and Evolutionary Constraints on Foraging. Chapman and Hall, New York, pp. 170-220.

Murcia C. 1995: Edge effects in fragmented forests: implications for conservation. - Trends Ecol. Evol. 10: 58-62.

Novotny V., Basset Y., Auga J., Boen W., Dal C., Drozd P., Kasbal M., Isua B., Kutil R. \& Manumbor M. 1999: Predation risk for herbivorous insects on tropical vegetation: A search for enemy-free space and time. - Aust. J. Ecol. 24: 477-483.

Novotny V., Drozd P., Miller S.E., Kulfan M., Janda M., BASSET Y. \& Weiblen G.D. 2006: Why are there so many species of herbivorous insects in tropical rainforests? - Science 313: 1115-1118.

Oksanen J., Blanchet F.G., Kindt R., Legendre P., Minchin P.R., O'Hara R.B., Simpson G.L., Solymos P., Stevens M.H.H. \& Wagner H. 2011: Community Ecology Package. R package version 2.0-1.

OLSON D.M. 1992: Rates of predation by ants (Hymenoptera: Formicidae) in the canopy, understory, leaf litter, and edge habitats of a lowland rainforest in Southwestern Cameroon. In Halle F. \& Pascal O. (eds): Biologie d'une Canopée de Forêt Équatoriale. Réserve de Campo, Cameroon, pp. 101-109.

Olsson O., Wiktander U., Malmqvist A. \& NiLSSON S.G. 2001: Variability of patch type preferences in relation to resource availability and breeding success in a bird. - Oecologia 127: 435-443.

Potthoff M., Johst K., Gutt J. \& Wissel C. 2006: Clumped dispersal and species coexistence. - Ecol. Modell. 198: 247-254.

R Development Core Team 2009: $R$ : A Language and Environment for Statistical Computing. R Foundation for Statistical Computing, Vienna, URL http://www.R-project.org. 
Remmel T. \& Tammaru T. 2009: Size-dependent predation risk in tree-feeding insects with different colouration strategies: a field experiment. - J. Anim. Ecol. 78: 973-980.

Remmel T., Davison J. \& TAmmaru T. 2011: Quantifying predation on folivorous insect larvae: the perspective of life-history evolution. - Biol. J. Linn. Soc. 104: 1-18.

Richards L.A. \& Coley P.D. 2007: Seasonal and habitat differences affect the impact of food and predation on herbivores: a comparison between gaps and understory of a tropical forest. - Oikos 116: 31-40.

RIECHERT S.E. \& LAWRENCE K. 1997: Test for predation effects of single versus multiple species of general predators: spiders and their insect prey. - Entomol. Exp. Appl. 84: 147-155.

Sin A., Ziemba R. \& Harding K.C. 2000: New insights on how temporal variation in predation risk shapes prey behavior. Trends Ecol. Evol. 15: 3-4.

ŠIPoš J., Drozdová M. \& Drozd P. 2011: Effect of canopy openness on the pressure of predatory arthropods and birds on epigeic insects. - Cent. Eur. J. Biol. 7: 1021-1029.

SIPURA M. 1999: Tritrophic interactions: willows, herbivorous insects and insectivorous birds. Oecologia 121: 537-545.

Skelhorn J. \& Rowe C. 2006: Predator avoidance learning of prey with secreted of stored defences and the evolution of insect defences. - Anim. Behav. 72: 827-834.

Skelhorn J., Rowland H.M., Delf J., Speed M.P. \& Ruxton G.D. 2011: Density-dependent predation influences the evolution and behavior of masquerading prey. - PNAS 108: $6532-6536$.

Stamp N.E. \& Bowers M.D. 1996: Consequences for hostplant chemistry and performance of plantain (Plantago lanceolata) when its herbivores are attacked by predatory wasps and stinkbugs. - Ecology 77: 535-549.

Steward V.B., Smith K.G. \& Stephen F.M. 1988: Predation by wasps on lepidopteran larvae in an Ozark forest canopy. Ecol. Entomol. 13: 81-86.

Strong A.M., Sherry T.W. \& Holmes R.T. 2000: Bird predation on herbivorous insects: indirect effects on sugar maple samplings. - Oecologia 125: 370-379.

Traniello J.F.A. 1989: Foraging strategies of ants. - Annu. Rev. Entomol. 34: 191-210.

Turchin P., TAYlor A.D. \& Reeve J.D. 1999: Dynamical role of predators in population cycles of a forest insect: an experimental test. - Science 285: 1068-1071.

Valladares G., Salvo A. \& Cagnolo L. 2006: Habitat fragmentation effects on trophic processes of insect-plan food webs. - Conserv. Biol. 20: 212-217.

WESELOH R.M. 1988: Effects of microhabitat, time of day, and weather on predation of gypsy moth larvae. - Oecologia 77: 250-254.

Wirth R., Meyer S.T., Leal I.R. \& Tabarelli M. 2008: Plant herbivore interactions at the forest edge. - Progr. Bot. 69: 423-448.

Wood S.N. 2006: Generalized Additive Models. An Introduction with R. Chapman \& Hall/CRC, Boca Raton, London, New York, $391 \mathrm{pp}$.

ZHENG D. \& CHEN J. 2000: Edge effects in fragmented landscapes: a generic model for delineating area of edge influences (D-AEI). — Ecol. Modell. 132: 175-190.

Received February 27, 2012; revised and accepted December 20, 2012 